Technology Development

Division

Technology Development

Division

Technology Development

Division

Technology Development

Division

Technology Development Division

Technology Development

Division

Techology Development

Division

"Techology Development

DWuston

Technology Development

ouvision

Technology Development

Division

Technology Development

Duvision

Technology Development

division

Technology Development

Division

Technology Development

Division

Technology Development

Fusion Option to Dispose of Spent Nuclear Fuel and Transuranic Elements

by Yousry Gohar

Fusion Power Program Technology Development Division

Drvision

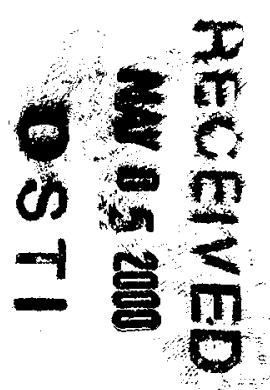

Technology Development

Division

Technology Development

Division

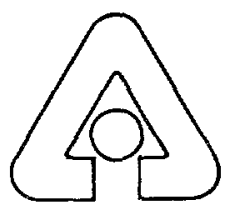

Argonne National Laboratory, Argonne, Illinois 60439

operated by The University of Chicago

for the United States Department of Energy under Contract W-31-109-Eng-38

Fusion power Program

Fusion Power Program

Fusion Power Program

Fusion Power program

Fusion Power Program

Fusion Pover Prograth

Fusion Power Program

Fusion Power program 
Argonne National Laboratory, with facilities in the states of Illinois and Idaho, is owned by the United States government, and operated by The University of Chicago under the provisions of a contract with the Department of Energy.

\section{DISCLAIMER}

This report was prepared as an account of work sponsored by an agency of the United States Government. Neither the United States Government nor any agency thereof, nor The University of Chicago, nor any of their employees or officers, makes any watranty, express or implied, or assumes any legal liability or responsibility for the accuracy, completeness, or usefulness of any information, apparatus, product, or process disclosed, or represents that its use would not infringe privately owned rights. Reference herein to any specific commercial product, process, or service by trade name, trademark, manufacturer, or otherwise, does not necessarily constitute or imply its endorsement, recommendation, or favoring by the United States Government or any agency thereof. The views and opinions of document authors expressed herein do not necessarily state or reflect those of the United States Government or any agency thereof, Argonne National Laboratory, or The University of Chicago.

Available electronically at http://www.doe.gov/bridge

Available for a processing fee to U.S. Department of Energy and its contractors, in paper, from:

U.S. Department of Energy

Office of Scientific and Technical Information

P.O. Box 62

Oak Ridge, TN 37831-0062

phone: (865) 576-8401

fax: (865) 576-5728

email: reports@adonis.osti.gov 


\section{DISCLAIMER}

Portions of this document may be illegible in electronic image products. Images are produced from the best available original document. 


\title{
FUSION OPTION TO DISPOSE OF SPENT NUCLEAR FUEL AND TRANSURANIC ELEMENTS
}

$$
\text { by }
$$

\section{Yousry Gohar}

Fusion Power Program/Technology Development Division

\author{
Argonne National Laboratory \\ 9700 South Cass Avenue \\ Argonne, IL 60439
}

TECHNOLOGY DEVELOPMENT DIVISION TECHNICAL MEMORANDUM NO. 9 FUSION POWER PROGRAM INTERNAL REFERENCE NO. 299

Work supported by the Office of Fusion Energy Sciences

U.S. Department of Energy under Contract W-31-109-Eng-38 


\section{TABLE OF CONTENTS}

Page

ABSTRACT.

1

I. Introduction ............................................................................

II. Background and Objectives ........................................................ 3

III. Fusion Neutrons ...................................................................... 4

IV. Fusion Blanket Concepts ....................................................... 5

V. Molten Salt Blanket Concept ......................................................... 8

VI. Fusion Reactor System for Disposing the US Inventory of the Spent Nuclear Fuel

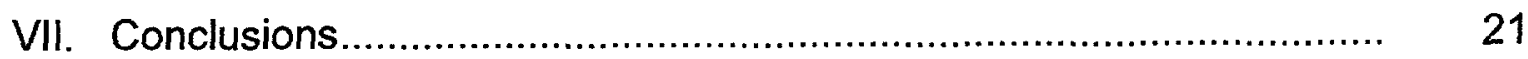

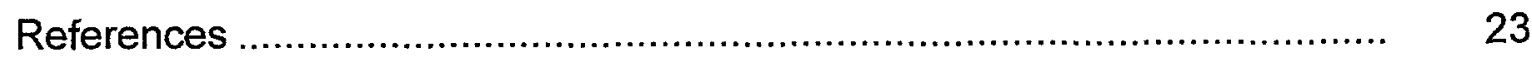

\section{LIST OF TABLES}

Table I The Main Physical Properties of Flibe $\left(\mathrm{Li}_{2} \mathrm{BeF}_{4}\right), \ldots \ldots \ldots \ldots \ldots \ldots . . . . . . . . \quad 9$

Table II Geometrical Blanket Model. ................................................. 10

Table III Flibe Blanket Performance Parameters without Transuranic Elements.

Table IV Flibe Blanket Performance Parameters with Natural Lithium and Different Concentration of the Transuranic Materials.

Table V Flibe Blanket Performance Parameters with Depleted Lithium-6 and Constant Concentration of the Transuranic Materials.

Table VI Flibe Blanket Performance Parameters with very Low

Concentration of $\mathrm{Li}-6$ and $\mathrm{PuF}_{3}$. 


\section{LIST OF FIGURES}

Figure No.

1 Solubility of $\mathrm{CeF}_{3}$ and $\mathrm{PuF}_{3}$ in $\mathrm{LiF}-\mathrm{BeF}_{2}$ molten salt at different temperatures - From reference 9.

2 Blanket energy multiplication factor (BEMF), total blanket energy multiplication factor (TEMF), and tritium breeding ratio (TBR) as function of the Flibe zone thickness.

3 Shield energy fraction (SEF) as function of the Flibe zone thickness.

4 Tritium breeding ratio as function of the $\mathrm{PuF}_{3}$ weight fraction in the Flibe molten salt.

$5 \quad$ Blanket energy multiplication factor (BEMF) and total energy multiplication factor (TEMF) as function of the $\mathrm{PuF}_{3}$ weight fraction in the Flibe molten salt.

6 Shield energy fraction (SEF) as function of the $\mathrm{PuF}_{3}$ weight fraction in the Flibe molten salt.

$7 \quad$ Number of fission reactions as function of the $\mathrm{PuF}_{3}$ weight fraction in the Flibe molten salt.

8 Plutonium transmutation rate as function of the $\mathrm{PuF}_{3}$ weight fraction in the Flibe molten salt.

9 Tritium breeding ratio as function of the lithium -6 fraction. ...

10 Blanket energy multiplication factor (BEMF) and total energy multiplication factor (TEMF) as function of the lithium -6 fraction.

11 Shield energy fraction (SEF) as function of the lithium -6 fraction.

12 Number of fission reactions as function of the lithium -6 fraction.

13 Plutonium transmutation rate as function of the lithium -6 fraction. 


\title{
Fusion Option to Dispose of Spent Nuclear Fuel and Transuranic Elements
}

\author{
Yousry Gohar
}

\begin{abstract}
The fusion option is examined to solve the disposition problems of the spent nuclear fuel and the transuranic elements. The analysis of this report shows that the top rated solution, the elimination of the transuranic elements and the longlived fission products, can be achieved in a fusion reactor. A $167 \mathrm{MW}$ of fusion power from a D-T plasma for sixty years with an availability factor of 0.75 can transmute all the transuranic elements and the long-lived fission products of the 70,000 tons of the US inventory of spent nuclear fuel generated up to the year 2015. The operating time can be reduced to thirty years with use of $334 \mathrm{MW}$ of fusion power, a system study is needed to define the optimum time. In addition, the fusion solution eliminates the need for a geological repository site, which is a major advantage. Meanwhile, such utilization of the fusion power will provide an excellent opportunity to develop fusion energy for the future. Fusion blankets with a liquid carrier for the transuranic elements can achieve a transmutation rate for the transuranic elements up to $80 \mathrm{~kg} / \mathrm{MW}$.y of fusion power with $\mathrm{k}_{\text {eff }}$ of 0.98 . In addition, the liquid blankets have several advantages relative to the other blanket options. The energy from this transmutation is utilized to produce revenue for the system. Molten salt (Flibe) and lithium-lead eutectic are identified as the most promising liquids for this application, both materials are under development for future fusion blanket concepts. The Flibe molten salt with transuranic elements was developed and used successfully as nuclear fuel for the molten salt breeder reactor in the 1960's.
\end{abstract}

The results from this analysis illustrate the great potential of the fusion option for solving the disposition problems of the spent nuclear fuel and the transuranic elements. The fusion option deserves a detailed investigation, which defines the different system components, identifies the technical issues that require resolution, 
proposes schedule and plan to resolve these issues, estimates the total cost of the system to dispose of the US inventory of spent nuclear fuel, and compares cost and schedule with the other options under consideration. The initial results show that the fusion option has several unique advantages and excellent performance for performing these functions. 


\section{Introduction}

The disposal of the nuclear spent fuel, the transuranic elements, and the highly enriched uranium represents a major problem under investigation by the international scientific community to identify the most promising solutions. Different fusion options $(1,2$, and 3$)$ were considered to resolve this problem where the analyses showed the fusion potential to perform this function. The investigation of this report concentrated on achieving the top rated solution of this problem, the elimination goal (4). This solution requires complete elimination for the transuranic elements and the long-lived fission products while avoiding the fabrication and processing of new fuel elements as much as possible. To achieve this goal, blankets with liquid carrier for the transuranic elements were considered. Analysis was performed as an example for one candidate blanket to define its performance and to size the required fusion system to solve the US spent nuclear fuel problem. Special attention was given to use existing technologies as much as possible to avoid expensive R\&D and to provide near term solution.

\section{Background and Objectives}

Fusion can provide a complete and attractive solution for the national and the international disposition problems of the spent nuclear fuel and the transuranic elements. In addition, the fusion technical requirements for these functions are very modest, as will be seen from the analysis. This will provide an excellent opportunity to develop fusion as an energy source for the future while providing a near term solution for these problems.

In the United States, the inventory of the spent nuclear fuel from the commercial power plants will reach 70,000 tons by the year of 2015 , including 7,000 tons from the fission reactors operated by the department of energy. In this spent nuclear fuel, a small fraction of the uranium fuel is utilized for energy production, producing fission products and transuranic elements. This inventory of spent nuclear fuel 
consists of about 67,000 tons of uranium, 600 tons of transuranic elements, and 2400 tons of fission products. Most of the fission products have relatively short half-lives, tens of years. To dispose the spent nuclear fuel, uranium, fission products, long lived fission products $\left(T c^{99}, \mathrm{I}^{129}\right.$, etc.), and transuranic elements are separated. Uranium can be recycled in fresh fuel or disposed as low-level radioactive waste (Class- $\mathrm{C}$ waste). The fission products will be processed for disposal in a temporary repository to decay. The long-lived fission products will be fabricated into fission product targets for transmutation in fusion reactors utilizing the neutron leakage from the fusion blanket to the shields. The transuranic elements will be fissioned in fusion blankets where energy will be produced to generate revenue for the system.

Also, fusion option can be used to dispose of the current inventory of transuranic elements by utilizing its energy content and transmuting its long lived fission products, which represents a complete and attractive solution for this problem. The current inventory is about 135 tons of transuranic elements processed from spent nuclear fuel, about 1400 tons of highly enriched uranium, and 100 to 260 tons of plutonium.

The main objective of this investigation is to introduce and to quantify the fusion solution to eliminate the transuranium elements and the long-lived fission products, to minimize the radioactive waste volume, to utilize the fission energy from the transuranic elements for offsetting the disposal cost and generate revenue, and to eliminate the need of geological repository. In the investigation, D-T neutrons are used for achieving these goals with minimum fusion power.

\section{Fusion Neutrons}

Fusion neutrons from D-T plasma have several characteristics that result in attractive performance for such applications. The spatial distribution reduces the power density in the blanket materials, which facilitates the heat removal process. 
Most of the fusion energy, $\sim 80 \%$, are carried by the D-T neutrons that reduces the first wall surface heat flux of the fusion blanket. The high neutron energy enhances the neutron multiplication through $(n, 2 n),(n, 3 n)$, and fast fission reactions, which increases the disposal rate of the transuranic elements and the transmutation rate of the long-lived fission products. This combination of features is unique for fusion neutrons relative to other possible sources, point sources or low energy distributed sources, which enhance the performance of the fusion solution for solving these problems.

\section{Fusion Blanket Concepts}

A fast neutron spectrum has neutronics advantages for transmuting the transuranic elements relative to thermal neutron spectrum including higher fission reaction rate per fusion neutron, efficient neutron production and utilization with high concentration of fission products, and low probability for generating high actinides. The neutron leakage from the blanket can be thermalized and utilized for transmuting the long-lived fission products. These advantages favor fusion blankets with fast neutron spectrum for achieving high performance for these applications. In addition, the large change in the blanket thermal output during operation due to the concentration change of the transuranic elements, and the desire to operate at constant fusion power and blanket thermal output for power generation promote the use of fusion blanket concepts capable of continuously mixing and adjusting the concentration of the transuranic elements. Also, the possibility of removing fission products during operation to increase the neutron utilization for eliminating the transuranic elements and the transmutation rate of the long-lived fission products lead to the consideration of fusion blankets with mobile carrier for the transuranic elements. Molten salts and liquid metal eutectics are the preferred carriers that result in a blanket operation with fast neutron spectrum. Aqueous carriers are excluded because of its neutron slowing down characteristics. Solid carrier is another possibility, but it is not considered in this analysis because of the fabrication and reprocessing requirements. 
Molten fuel salt (5 and 6 ) was developed and used for fission reactors. Flibe molten salt $\left(\mathrm{Li}_{2} \mathrm{BeF}_{4}\right)$ was selected and used for the Molten Salt Breeder Reactor (MSBR). Molten salt technologies were developed for MSBR in the 1960's, for the fuel cycle of the fast breeder program in the 1990's, and for decommissioning the molten fuel salt of the MSBR in the 1990's. Also, fusion reactors are considering Flibe as a tritium breeder and coolant for magnetic and inertial confinement concepts. Flibe molten salt with plutonium fluoride $\left(\mathrm{PuF}_{3}\right)$ can be used as tritium breeder, transuranic carrier, neutron multiplier, and coolant for the fusion blanket.

Lithium-Lead eutectic (17 $\mathrm{Li}-83 \mathrm{~Pb})$ is under development as a breeder and coolant for fusion reactors (7 and 8 ). Lithium-Lead eutectic posses several attractive features including low melting point $\left(235^{\circ} \mathrm{C}\right)$, good neutron multiplication performance, low parasitic absorption cross section, acceptable material compatibility with the steel structure, and an acceptable safety performance: Similar to Flibe, Lithium-Lead eutectic can be used as a carrier for the transuranic elements. For this application, the lithium-lead has the advantage of less slowing down characteristics for the fusion neutrons due to the absence of beryllium, which improves the blanket performance.

Both blanket concepts can use a continuous feed of transuranic elements, which allows the blanket to maintain a constant thermal output. Solid fusion blankets require frequent material shuffling and replacement to readjust the spatial distribution of the transuranic elements for maintaining a minimum thermal output. The replaced materials need processing to separate the unfissioned transuranic elements, the fission products, and the long-lived fission products for recycling in the system. For these reasons, this investigation concentrated on the liquid blankets as an example for the fusion solution. In addition, liquid fusion blankets possess several unique attractive features, which result in excellent performance for this application. The following are the main characteristics that enhance the attractiveness of the liquid fusion blankets for this application: 
- The liquid blanket can operate at constant thermal output at any power level by adjusting the liquid composition (transuranic elements and lithium enrichment), which is an essential requirement for power generation.

- The blanket mode of operation achieves the elimination goal, which is the most attractive option for the disposal of the spent nuclear fuel and the transuranic elements.

- Both, Flibe and Lithium-Lead liquids require low-pressure system. This low-pressure requirement reduces the primary stresses in the blanket structure, which improves the blanket design and performance.

- Development and fabrication costs of solid transuranic materials are eliminated. This also represents a significant attractive feature for the security control of the transuranic elements.

- Burnup limit for the transuranic elements due to radiation effects is eliminated, which permits achieving the elimination goal for the transuranic elements.

- Heat is generated within the liquid, which simplifies the heat removal process without generating thermal stresses.

- Both, Flibe and Lithium-Lead liquids have large negative temperature coefficient with respect to the blanket reactivity, which enhances the safety performance of the fusion reactor.

- $\quad$ Both, Flibe and Lithium-Lead liquids are chemically and thermally stable under irradiation conditions, which minimizes the radioactive waste volume and allows the elimination goal for the transuranic elements.

- The operational record of the molten salt fission reactor was very successful, which minimizes the technical risk using this option.

- Uranium, Thorium, and Plutonium were used as source of power in the operation of the molten salt fission reactor that established the technical bases for this selection.

The operation of the liquid blankets requires chemical control methods to insure material compatibility with the structural material and to reduce the tritium 
permeation from the system to an acceptable level. Several methods were successfully tested, however these methods have to be reassessed for operation with magnetic field and fission products. This report will address only the molten salt concept in detail as an example for the fusion option.

\section{Molten Salt Blanket Concept}

The self-cooled molten salt blanket concept is considered as an example to quantify the performance of the fusion solution. In addition, the results from this analysis are used to size the required fusion system to solve the United State spent fuel problem. Flibe was characterized for the molten salt fission reactor program in 1960's including the physical properties, the corrosion issue, the chemical processing, and the solubility of the fuel compounds and the fission products in the salt $(7,8$, and 9$)$. The salt properties used in the analysis are summarized in this section. Table I gives the main physical properties of the Flibe salt. $\mathrm{UF}_{4}, \mathrm{ThF}_{4}$, and $\mathrm{PuF}_{3}$ are the fuel compounds selected for the molten salt reactor. For this analysis, $\mathrm{PuF}_{3}$ is the material of interest. $\mathrm{PuF}_{3}$ is a solid with a density of $9.32 \mathrm{~g} / \mathrm{cm}^{3}$ and it has a melting point of $1425^{\circ} \mathrm{C}$. The solubility of $\mathrm{PuF}_{3}$ in Flibe was measured (9) for composition ranging in $\mathrm{BeF}_{2}$ from 28.7 to 48.3 mole in the temperature range of 450 to $650^{\circ} \mathrm{C}$. Figure 1 shows the solubility of $\mathrm{PuF}_{3}$ and $\mathrm{CeF}_{3}$ in $\mathrm{LiF}_{-\mathrm{BeF}_{2}}$ molten salt at different temperatures. In the parametric analysis, the $\mathrm{PuF}_{3}$ weight fraction in the salt was varied in the range of 0.0025 to 0.0275 ( 0.084 to 0.94 Mole \%) to reflect the data presented in Figure 1. 
Table I. The Main Physical Properties of Flibe $\left(\mathrm{Li}_{2} \mathrm{BeF}_{4}\right)$.

Melting point, ${ }^{\circ} \mathrm{C}$

459.1

Thermal conductivity, $\mathrm{W} / \mathrm{cm} .{ }^{\circ} \mathrm{C}$

0.010

Viscosity, centipoises

$0.116 \exp \left[3755 / \mathrm{T}\left({ }^{\circ} \mathrm{k}\right)\right]$

Electrical conductivity at $500, \mathrm{ohm}^{-1} \mathrm{~cm}^{-1}$

$9.210^{-3}$

Heat capacity, cal/g. ${ }^{\circ} \mathrm{C}$

0.57

Density, $\mathrm{g} / \mathrm{cm}^{3}$

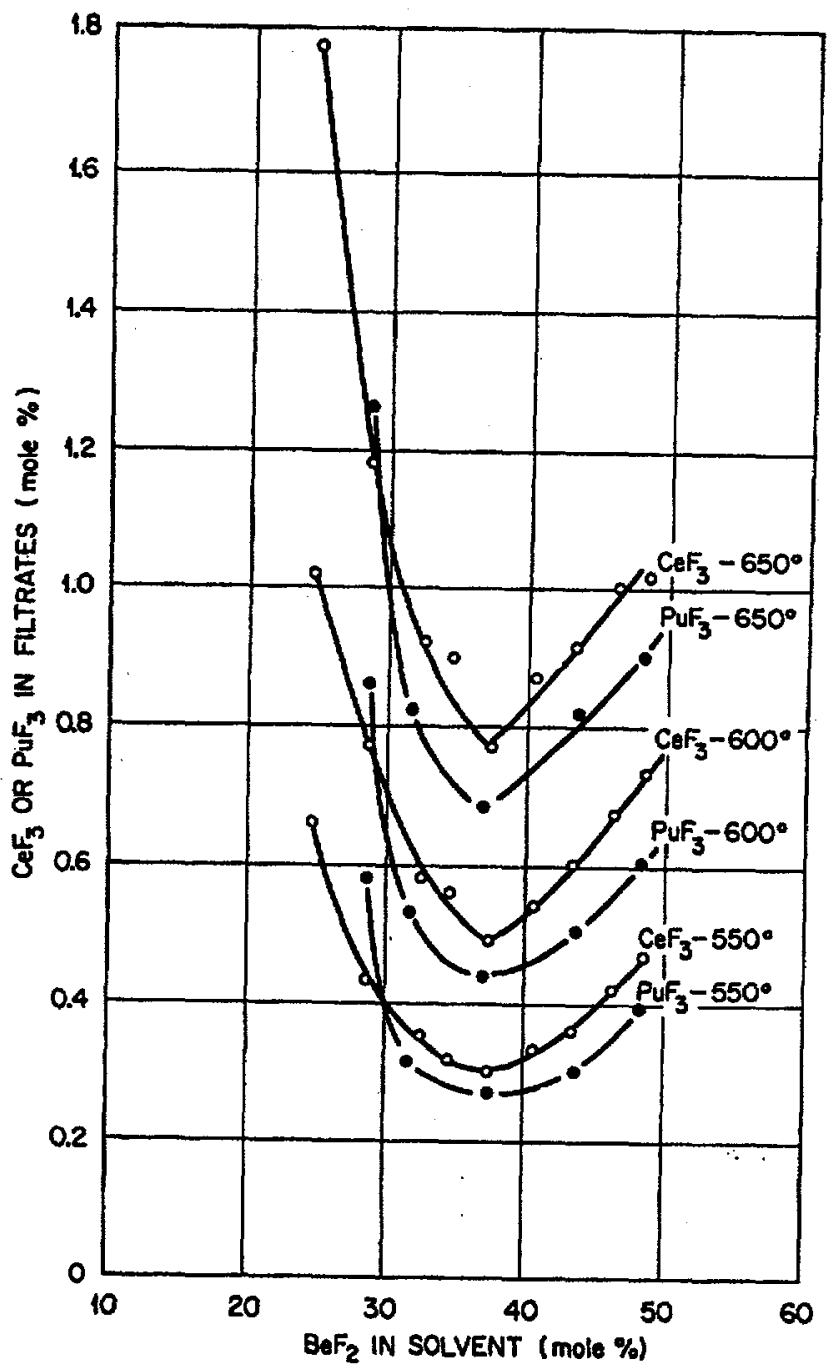

Figure 1. Solubility of $\mathrm{CeF}_{3}$ and $\mathrm{PuF}_{3}$ in $\mathrm{LiF}_{-} \mathrm{BeF}_{2}$ molten salt at different temperatures - From reference 9 . 
A simple poloidal blanket configuration is considered where the inlet and the outlet manifolds are located at the top section of the reactor. The salt coolant is introduced first to the front section of the blanket to remove the surface heat flux from first wall. Then, the flow direction changes at the bottom to leave the blanket module at the top. This flow pattern simplifies the reactor manifold system.

At the reactor startup, it is foreseen to operate the blanket without transuranic elements to confirm and calibrate the operation of the different reactor systems. This mode of operation reduces the shielding capability of the blanket due to the absence of the neutron absorber, the transuranic elements. Therefore, the blanket performance was first defined with pure Flibe salt as a function of the blanket radial thickness. The blanket configuration used to perform this analysis is given in Table II where the Flibe zone thickness was varied from 0.2 to $0.6 \mathrm{~m}$. The performance parameters of this type of blanket are displayed in Figures 2 and 3. A 0.5-m Flibe zone thickness is required to reduce the energy deposition in the shield to $\sim 4 \%$ of the total blanket and shield energy deposition. At this blanket thickness, the other performance parameters, the tritium-breeding ratio (TBR) and the blanket energy multiplication are very close to the saturation values. Table III gives the performance parameters for the blanket with $0.5-\mathrm{m}$ Flibe zone, which considered for more detail analysis with the transuranic elements.

Table II. Geometrical Blanket Model.

\begin{tabular}{|l|l|}
\hline Zone & Material - Dimension \\
\hline First wall & Type 316 stainless steel $-0.05 \mathrm{~m}$ \\
\hline Breeder/Coolant & Flibe with natural lithium -0.2 to $0.6 \mathrm{~m}$ \\
\hline Structure & Type 316 stainless steel $-0.01 \mathrm{~m}$ \\
\hline Shield & Steel shield $\left(80 \%\right.$ Type 316 Austenitic steel and $\left.20 \% \mathrm{H}_{2} \mathrm{O}\right)$ \\
\hline
\end{tabular}




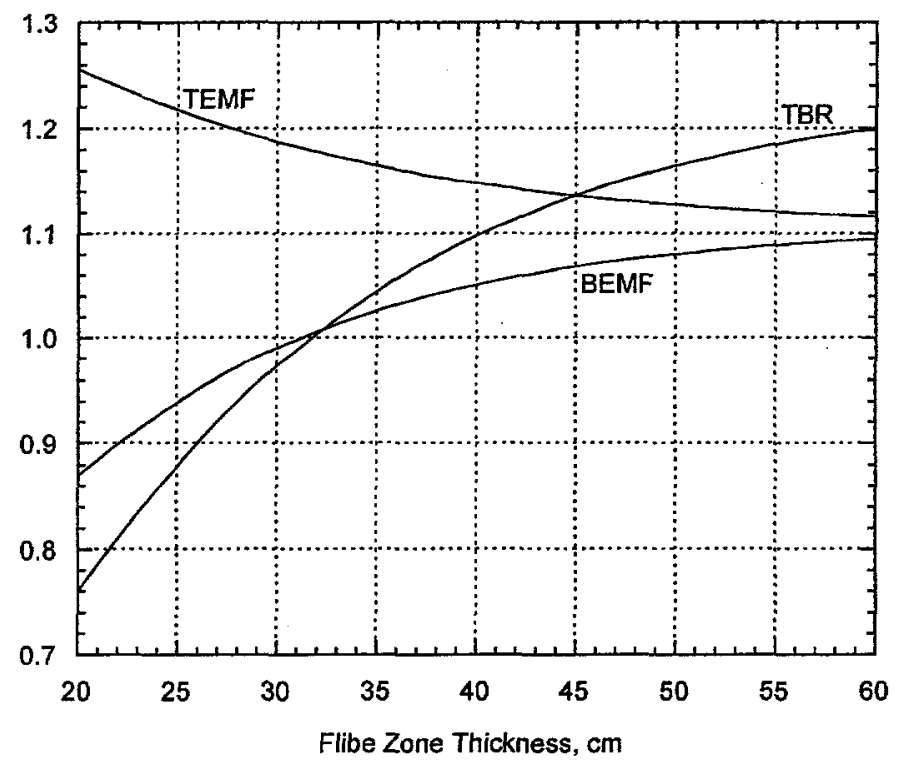

Figure 2. Blanket energy multiplication factor (BEMF), total blanket energy multiplication factor (TEMF), and tritium breeding ratio (TBR) as function of the Flibe zone thickness.

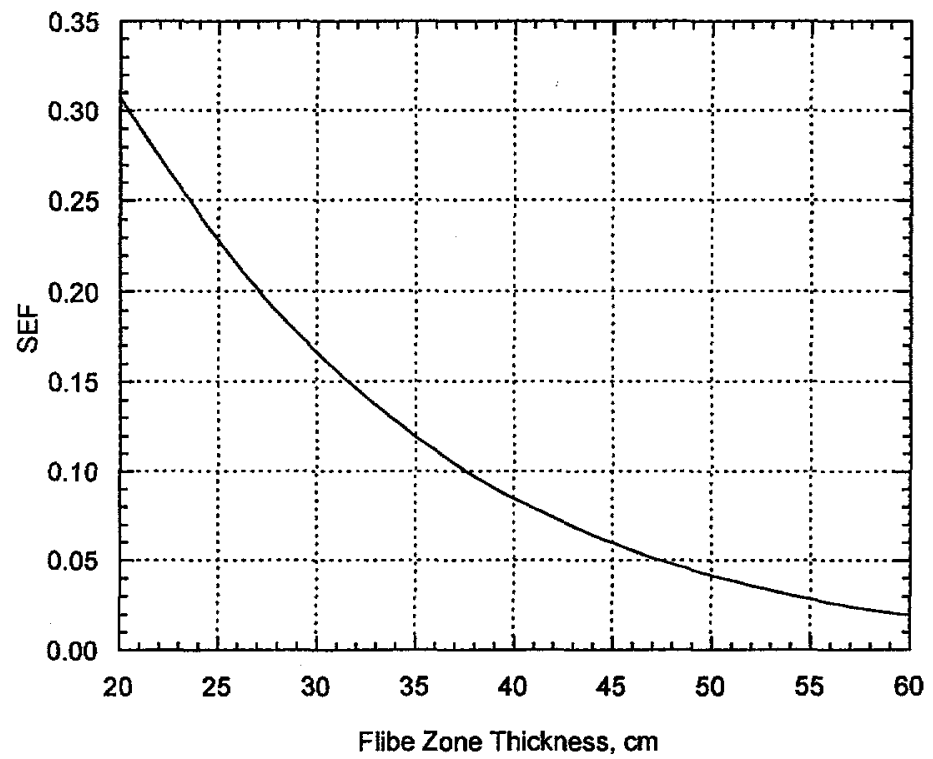

Figure 3. Shield energy fraction (SEF) as function of the Flibe zone thickness. 
Table III. Flibe Blanket Performance Parameters without Transuranic Elements.

\begin{tabular}{|ll|}
\hline Total blanket thickness, $m$ & 0.515 \\
Blanket energy multiplication factor & 1.080 \\
Local tritium breeding ratio & 1.127 \\
Shield energy fraction & 0.041 \\
\hline
\end{tabular}

The second step in this analysis is to define the performance of the $0.515-\mathrm{m}$ blanket with $\mathrm{PuF}_{3}$ dissolved in the Flibe. The $\mathrm{PuF}_{3}$ weight fraction was varied in the range of 0.0025 to 0.0275 based on the experimental results explained before. The blanket configuration of Table II is used for the analysis with $0.5-\mathrm{m}$ Flibe zone thickness. The results are displayed in Figures 4 through 8 . Table IV summarizes the main blanket performance parameters for the lower and the upper concentration values of $\mathrm{PuF}_{3}$. As the $\mathrm{PuF}_{3}$ concentration in the Flibe salt increases, all the blanket performance parameters increase as shown in Table IV. At the highest concentration, the plutonium transmutation rate is $4.4 \mathrm{~kg} / \mathrm{MW}$.y of fusion power. The corresponding tritium-breeding ratio and the blanket energy multiplication factor are 2.2 and 15.3, respectively. This high tritium-breeding ratio indicates that the lithium- 6 concentration can be reduced to increase the plutonium transmutation rate and to reduce the tritium-breeding ratio. In addition, the maximum $k_{\text {eff }}$ of this blanket is 0.741 , which provides a large margin to enhance the neutron multiplication and the transmutation rate while maintaining sub-critical operation. 


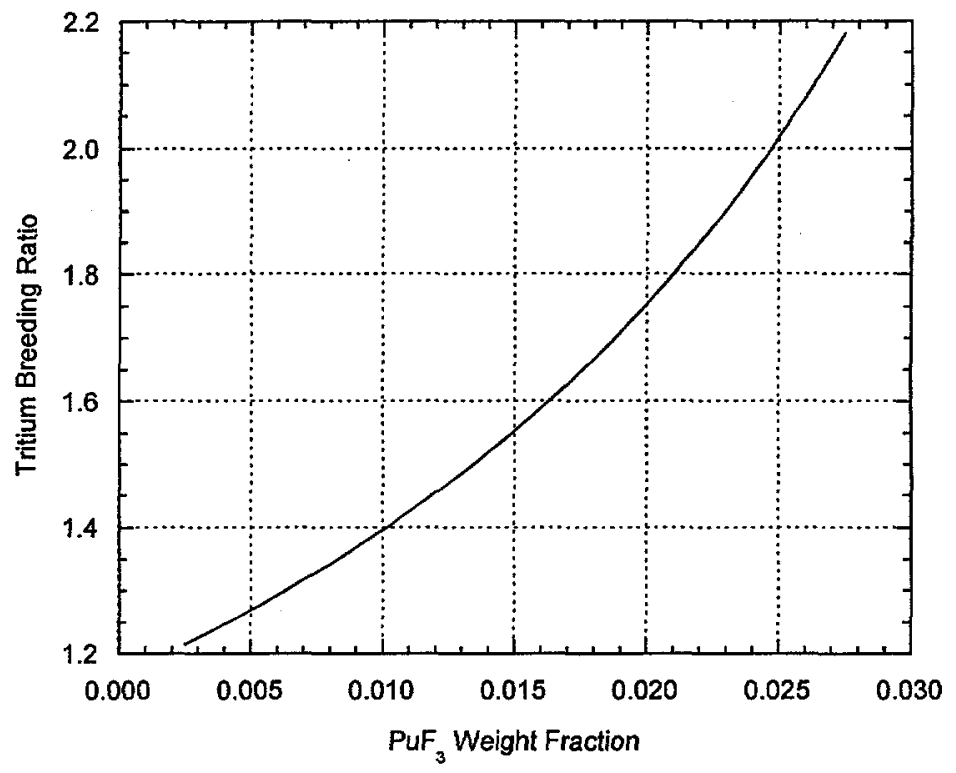

Figure 4. Tritium breeding ratio as function of the $\mathrm{PuF}_{3}$ weight fraction in the Flibe molten salt.

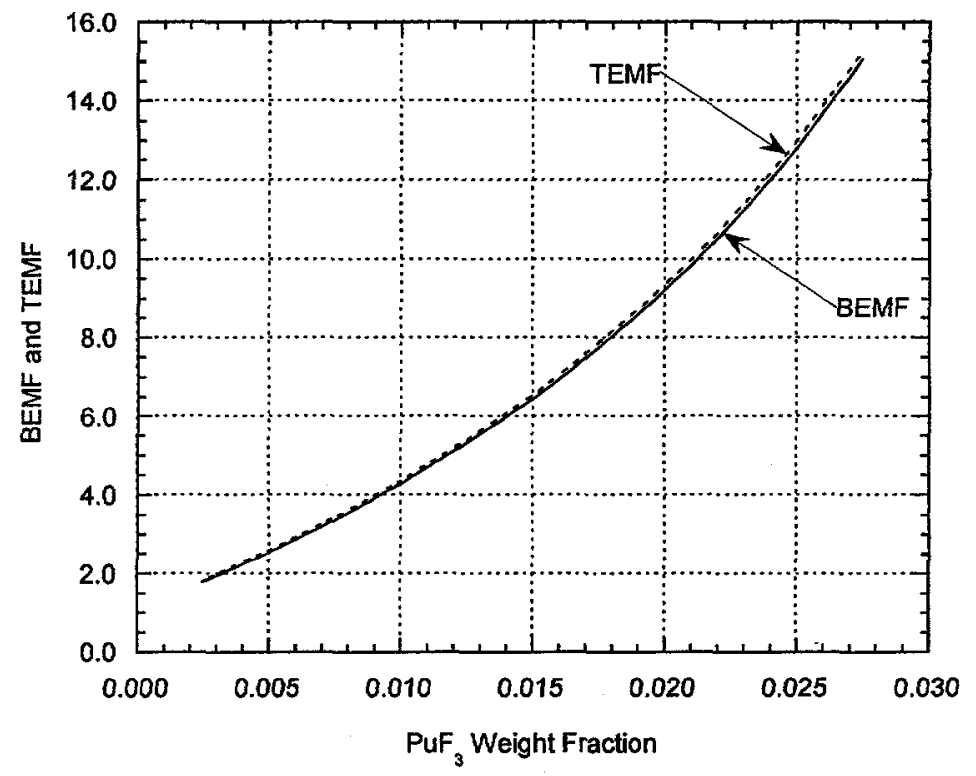

Figure 5. Blanket energy multiplication factor (BEMF) and total energy multiplication factor (TEMF) as function of the $\mathrm{PuF}_{3}$ weight fraction in the Flibe molten salt. 


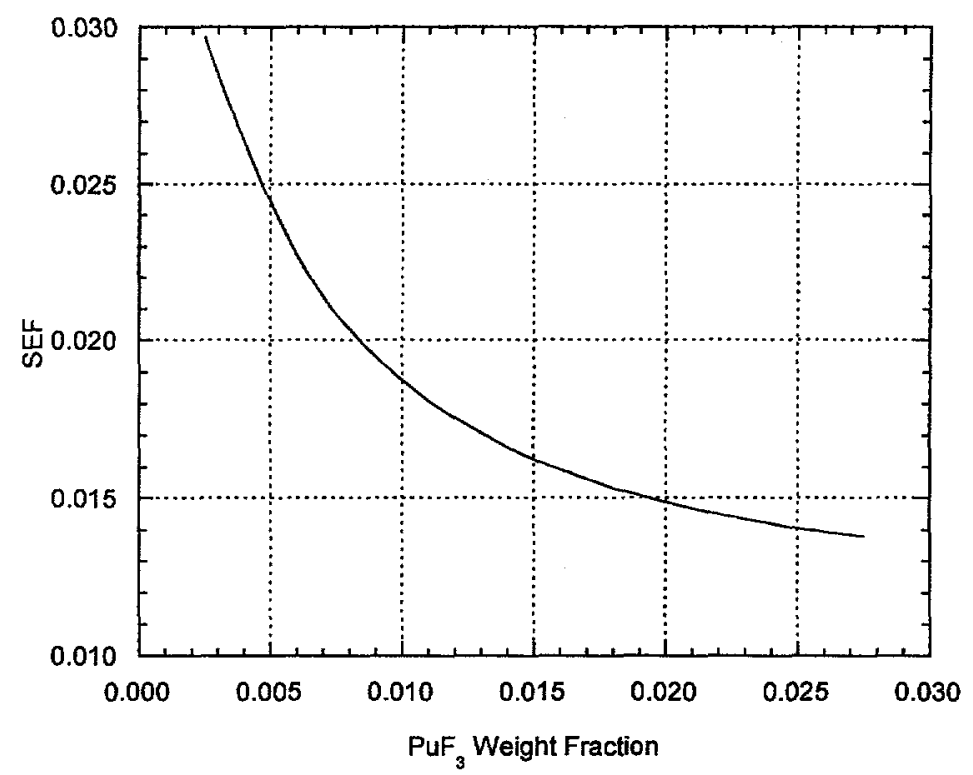

Figure 6. Shield energy fraction (SEF) as function of the $\mathrm{PuF}_{3}$ weight fraction in the Flibe molten salt.

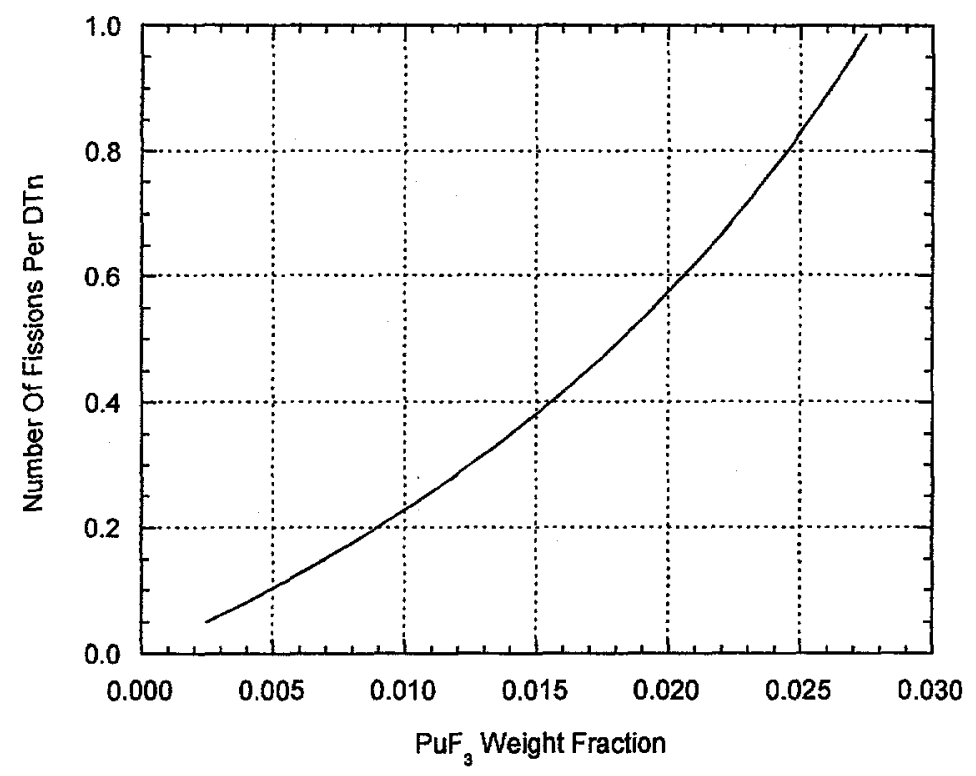

Figure 7. Number of fission reactions as function of the $\mathrm{PuF}_{3}$ weight fraction in the Flibe molten salt. 


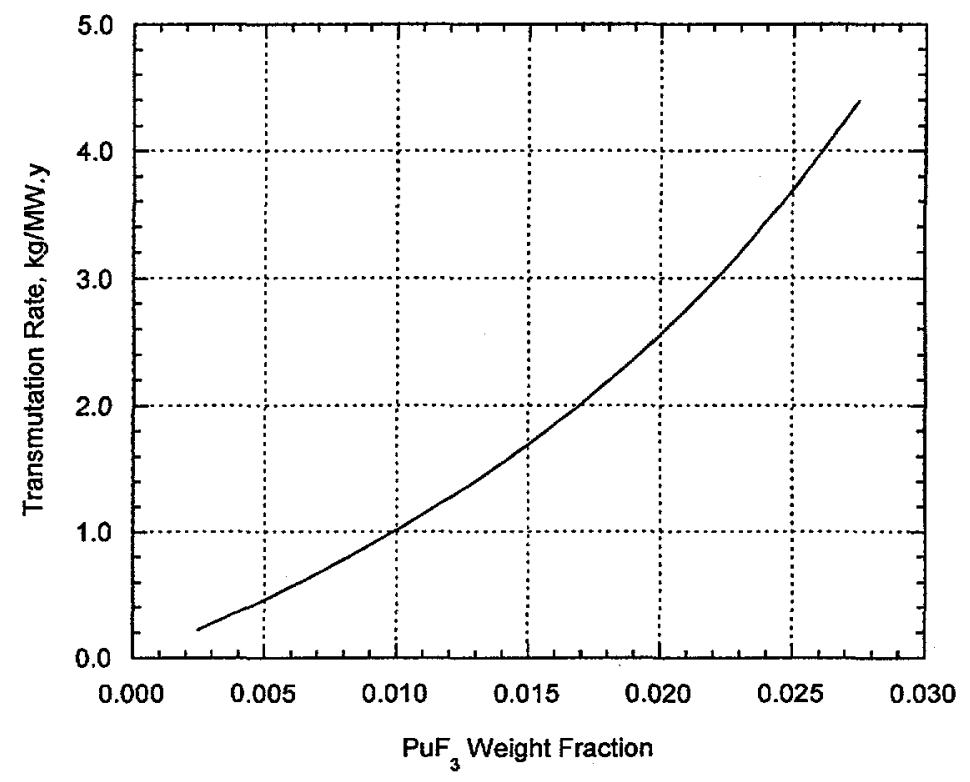

Figure 8. Plutonium transmutation rate as function of the $\mathrm{PuF}_{3}$ weight fraction in the Flibe molten salt.

Table IV. Flibe Blanket Performance Parameters with Natural Lithium and Different Concentration of the Transuranic Materials.

\begin{tabular}{|l|c|c|}
\hline $\mathrm{PuF}_{3}$ weight fraction & 0.0025 & 0.0275 \\
\hline Lithium-6 enrichment & Natural & Natural \\
Total blanket thickness, $\mathrm{m}$ & 0.515 & 0.515 \\
Blanket energy multiplication factor & 1.765 & 15.052 \\
Total energy multiplication factor & 1.819 & 15.262 \\
Local tritium breeding ratio & 1.214 & 2.180 \\
Shield energy fraction & 0.030 & 0.014 \\
Number of fission reactions per D-T neutron & 0.049 & 0.986 \\
Plutonium transmutation rate, kg/MW.y & 0.219 & 4.390 \\
Keff & 0.125 & 0.741 \\
\hline
\end{tabular}


The blanket configuration of Table II is analyzed with constant $\mathrm{PuF}_{3}$ concentration in the Flibe salt of 0.024 weight fraction. The lithium- 6 concentration was varied from 2.5 to $7.5 \%$ in the analysis. The blanket performance parameters are displayed in Figures 9 through 13. As the lithium- 6 concentration is reduced, the blanket performance parameters are improved. The plutonium transmutation rate is increased from 3.4 to $48 \mathrm{~kg} / \mathrm{MW}$.y as the lithium- 6 concentration is reduced from $7.5 \%$, natural lithium, to $2.5 \%$. However, the local tritium-breeding ratio is very high, it reached 10.8 for the $2.5 \%$ lithium- 6 concentration as shown in Table V. This suggests that the $2.5 \%$ lithium- 6 concentration is high and it can be reduced allowing more neutrons for transmuting plutonium. In addition, the $\mathrm{K}_{\text {eff }}$ of the blanket is 0.969 with the $2.5 \%$ lithium-6, which maintains sub-critical blanket operation. Also, the $\mathrm{PuF}_{3}$ concentration can be reduced, which enhances the safety characteristics of the blanket. The blanket energy multiplication factor reaches 160 , which provides good revenue to recover the transmutation cost. These results show the possibility of operating the blanket with very low concentrations for the lithium- 6 and $\mathrm{PuF}_{3}$.

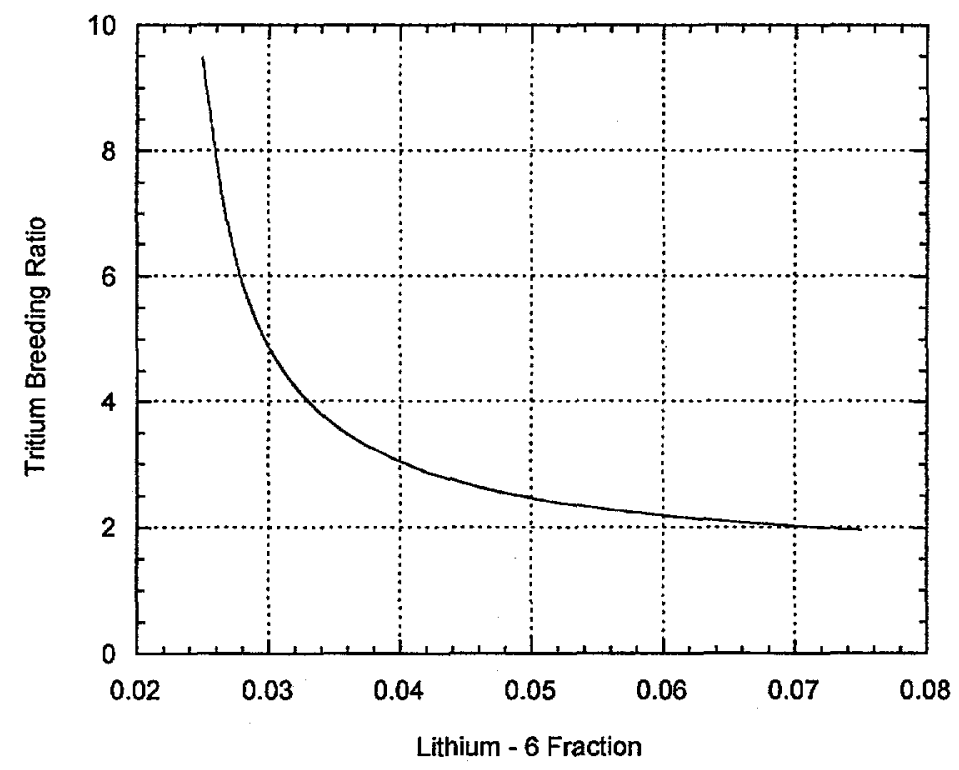

Figure 9. Tritium breeding ratio as function of the lithium -6 fraction. 


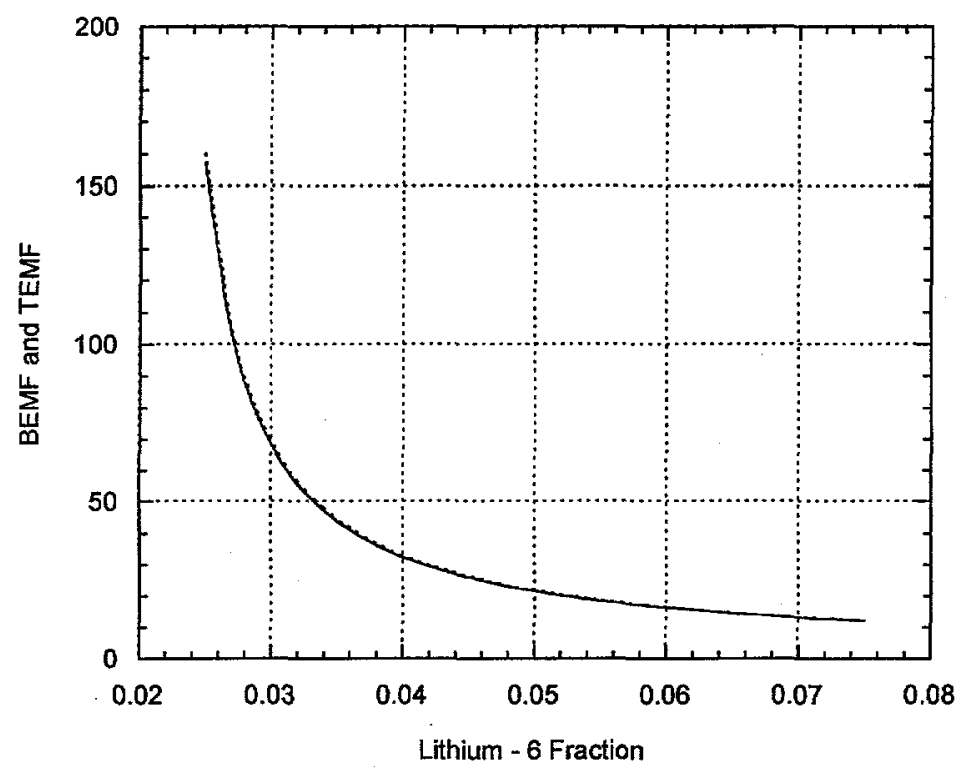

Figure 10. Blanket energy multiplication factor (BEMF) and total energy multiplication factor (TEMF) as function of the lithium -6 fraction.

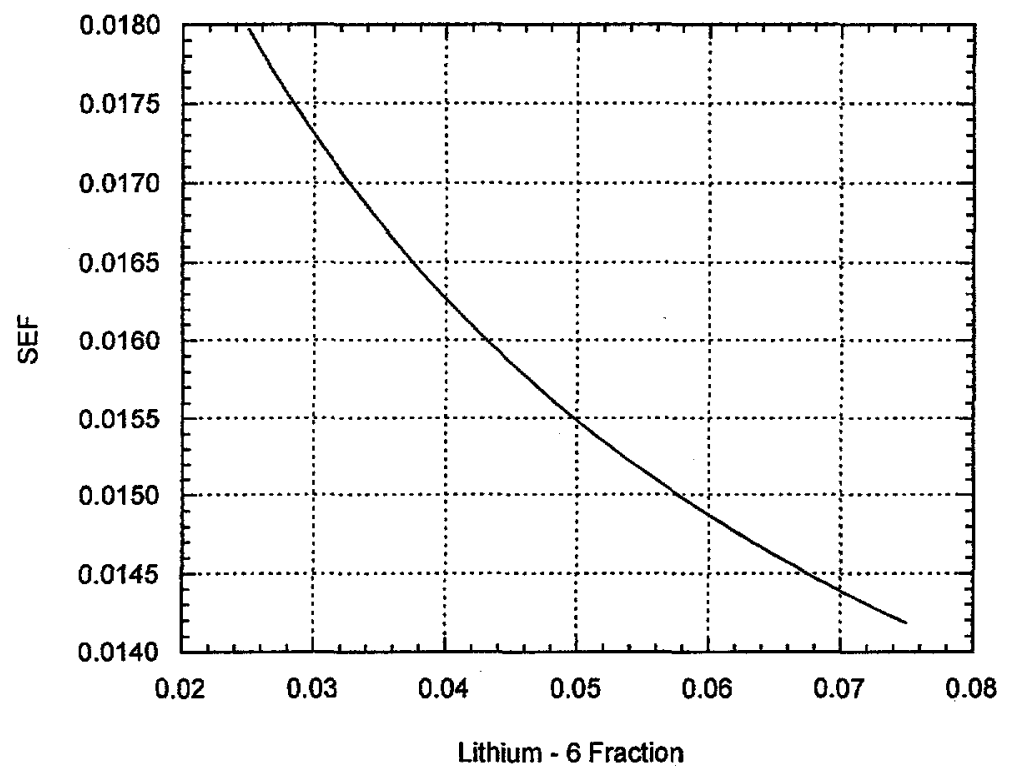

Figure 11. Shield energy fraction (SEF) as function of the lithium - 6 fraction. 


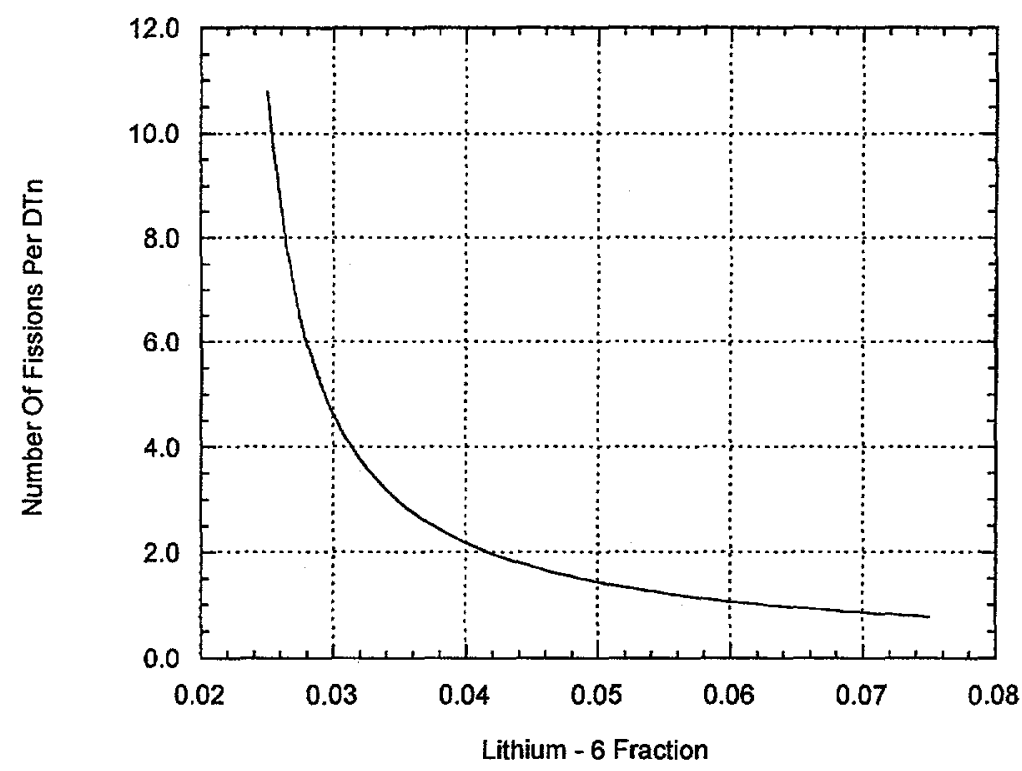

Figure 12. Number of fission reactions as function of the lithium - 6 fraction.

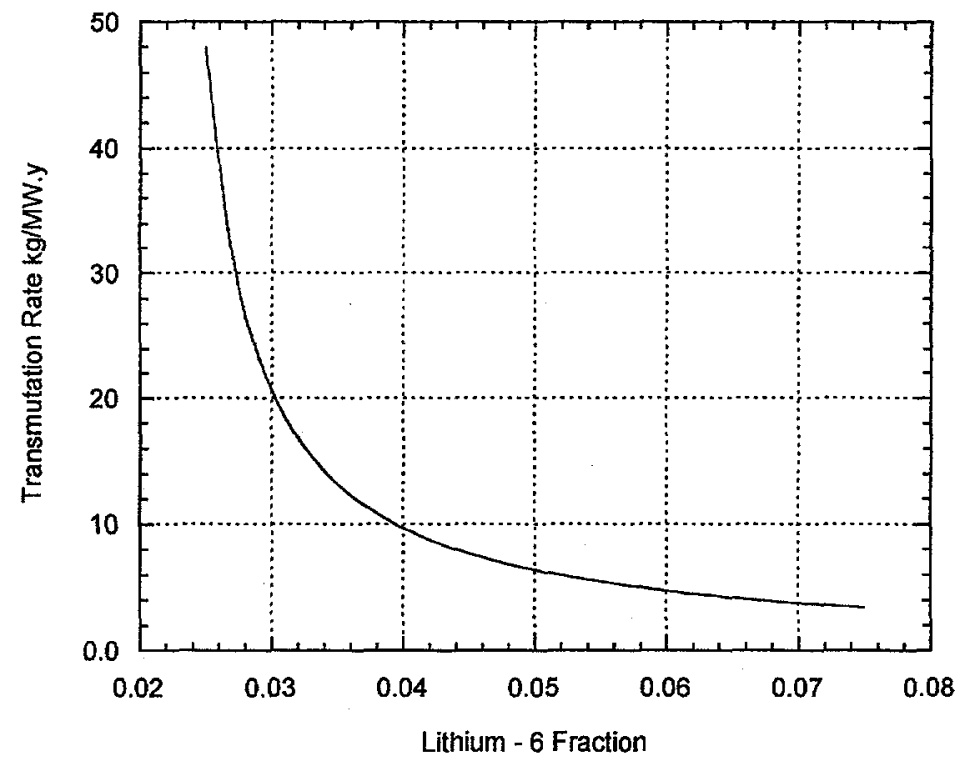

Figure 13. Plutonium transmutation rate as function of the lithium - 6 fraction. 
Table V. Flibe Blanket Performance Parameters with Depleted Lithium-6 and Constant Concentration of the Transuranic Materials.

\begin{tabular}{|l|c|c|}
\hline Lithium-6 enrichment, \% & 2.5 & 7.5 (Natural) \\
\hline PuF $_{3}$ weight fraction & 0.024 & 0.024 \\
Total blanket thickness, $\mathrm{m}$ & 0.515 & 0.515 \\
Blanket energy multiplication factor & 157.2 & 11.98 \\
Total energy multiplication factor & 160.0 & 12.15 \\
Local tritium breeding ratio & 9.469 & 1.956 \\
Shield energy fraction & 0.018 & 0.014 \\
Number of fission reactions per D-T neutron & 10.78 & 0.770 \\
Plutonium transmutation rate, kg/MW.y & 47.98 & 3.428 \\
Keff & 0.969 & 0.691 \\
\hline
\end{tabular}

The blanket configuration in Table II is analyzed with $100 \%$ lithium-7 and the $\mathrm{PuF}_{3}$ weight fraction in the Flibe salt is allowed to vary to achieve sub-critical operation at $\mathrm{K}_{\text {eff }}$ of 0.98 . Table $\mathrm{VI}$ gives the performance parameters for such blanket configuration. The plutonium transmutation rate is $72.6 \mathrm{~kg} / \mathrm{MW} . \mathrm{y}$, which is quite satisfactory. The blanket energy multiplication and the energy fraction in the shield are 242.6 and 0.018 . However, the tritium-breeding ratio of such blanket is 0.488 due to the absence of lithium- 6 . Therefore, a small concentration of lithium- 6 is included in the blanket, a value $0.25 \%$ is used. Again, the concentration of $\mathrm{PuF}_{3}$ is adjusted to reach $\mathrm{K}_{\text {eff }}$ of 0.98 . The obtained performance parameters are also given in Table VI, which are quite satisfactory. It should be clear that lithium- 6 acts as a burnable absorber in the blanket. As its concentration increases, the required concentration of $\mathrm{PuF}_{3}$ is increased to maintain the same $\mathrm{K}_{\text {eff }}$ value. The $0.25 \%$ lithium- 6 concentration in the lithium is an arbitrary value, it is possible to use a lower value. A system optimization is required to define the concentration of 
lithium-6 and $\mathrm{PuF}_{3}$ taken into consideration the system economics, safety concerns, and material issues. The initial lithium- 6 concentration decreases as the reactor operate as well as the $\mathrm{PuF}_{3}$ concentration. Since the tritium-breeding ratio with low concentration of lithium- 6 is very high that allows the reactor to operate without lithium- 6 for extended periods. Since the accumulated tritium will be more than adequate to insure tritium self-sufficiency.

Table VI. Flibe Blanket Performance Parameters with very Low Concentration of $\mathrm{Li}-6$ and $\mathrm{PuF}_{3}$.

\begin{tabular}{|l|c|c|}
\hline Lithium-6 enrichment, \% & 0.0 & 0.25 \\
$\mathrm{PuF}_{3}$ weight fraction & 0.00051 & 0.0056 \\
\hline Total blanket thickness, $\mathrm{m}$ & 0.515 & 0.515 \\
Blanket energy multiplication factor & 242.6 & 264.0 \\
Total energy multiplication factor & 251.5 & 270.9 \\
Local tritium breeding ratio & 0.488 & 10.740 \\
Shield energy fraction & 0.0352 & 0.0252 \\
Number of fission reactions per D-T neutron & 16.301 & 17.902 \\
Plutonium transmutation rate, kg/MW.y & 72.560 & 79.689 \\
K & 0.979 & 0.981 \\
\hline
\end{tabular}

VI. Fusion Reactor System for Disposing the US Inventory of the Spent Nuclear Fuel

The total amount of transuranic elements in the US inventory of the spent nuclear fuel will reach 600 tons by the year 2015. A molten salt fusion blanket with $k_{\text {eff }}$ of 0.98 can transmute $\sim 79.7 \mathrm{~kg}$ of transuranic elements per MW.y of fusion power. To transmute the total US inventory, a fusion fluence of $7528 \mathrm{MW} . \mathrm{y}$ is required. A 
single fusion reactor with $167 \mathrm{MW}$ of fusion power can provide such fluence over 60 years assuming an availability factor of 0.75 . However, the thermal output of this reactor will be $\sim 36294 \mathrm{MW}$, which is too large for a single unit. Instead, five fusion reactors $33.5 \mathrm{MW}$ of fusion power each will be more appropriate for such function. The thermal power from each reactor is $7258 \mathrm{MW}$, which generates a gross electrical power of $2468 \mathrm{MW}$. A $33.5 \mathrm{MW}$ fusion reactor can be constructed based on the current technology with driven plasma, which provides near term solution for the spent nuclear fuel disposition and an opportunity to develop fusion energy.

In addition, the previous analysis of the molten salt blanket shows that the transmutation rate and the blanket thermal output can be adjusted over a wide range, which provides a large flexibility to choose the reactor parameters including the fusion power level. Such flexibility is important factor for the long-term development of fusion reactors. For example, a larger fusion power can be used if it is required for the development of the plasma physics or the reactor technology where the concentration of the lithium- 6 or the transuranic elements can be adjusted to achieve the target values of thermal output, transmutation rate, and tritium breeding. Also, the number of the long-lived fission product targets inserted in the fusion reactor for transmutation can be adjusted to regulate the thermal output if it is required.

\section{Conclusions}

Fusion provides a very attractive option to solve the spent nuclear fuel and the plutonium disposition problems. Meanwhile, this utilization will provide an excellent opportunity to develop the fusion energy for the future. A $167 \mathrm{MW}$ of fusion power for sixty years with an availability factor of 0.75 can transmute all the transuranic elements and the long-lived fission products in the 70,000 tons of the US inventory of spent nuclear fuel generated up to the year 2015. Fusion blankets with liquid carrier for the transuranic elements can reach a transmutation rate up to 80 
$\mathrm{kg} / \mathrm{MW} . \mathrm{y}$ of fusion power. This type of blanket achieves the elimination goal, which is the top rated solution for the disposition of the transuranic elements and the long-lived fission products. The energy from the transmutation process is utilized to produce revenue for the system. In addition, the fusion solution eliminates the need for geological repository for the spent nuclear fuel, which is a major advantage. Flibe molten salt and lithium-lead eutectic are identified as the most promising liquids for this application where both materials are under development for future fusion blanket concepts.

Further analyses and studies are needed to develop such system considering previous work including non-fusion options. Definition of the different system components, identification of the technical issues that require resolution, schedule and plan to resolve these issues, total cost estimate of the system to dispose of the US inventory of spent nuclear fuel, and comparison with the other options under consideration need to be included in these studies. Blanket concept development requires special attention since its performance has a major impact on the whole system. In these studies, existing technologies will be utilized to minimize the R\&D cost and the schedule to complete the disposition process. 


\section{References}

1. T. A. Parish and J. W. Davidson, "Reduction in the Toxocoty of Fission Product Wastes Through Transmutation with Deutrium-Tritium Fusion Neutrons," Nuclear Technology, Vol. 47, February 1980.

2. W. M. Stacey, et al., "A Transmutation Facility for Weapons-Grade Plutonium Disposition Based on a Tokamak Fusion Neutron Source," Fusion Technology, Vol. 27, May 1995.

3. E. T. Cheng and R. J. Cerbone, "Prospect of Nuclear Waste Transmutation and Power Production in Fusion Reactors," Fusion Technology Vol. 30, December 1996.

4. Committee on International Security and Arms Control, "Management and Disposition of Excess Weapons Plutonium," National Academy of Science, Washington, D. C., National Academy Press, 1995.

5. J. R. McWherter, "Molten Salt Breeder Experiment Design Bases," Oak Ridge National Laboratory Report, ORNL-TM-3177, November 1970.

6. R. E. Thoma, "Chemical Aspects of MSRE Operation," Oak Ridge National Laboratory Report, ORNL-4658, December 1971.

7. D.L. Smith, et al., Blanket comparison and selection study - Final report, Argonne National Laboratory report, ANL/FPP-84-1 (1984).

8. L. Giancarli, G.Benamati, M. Fütterer, G. Marbach, C. Nardi, and J. Reimann, "Development of the EU Water-Cooled PB-17Li Blanket," Fusion Engineering and Design 39-40 (1998).

9. R. E. Thoma, "Chemical Feasibility of Fueling Molten Salt Reactors with $\mathrm{PuF}_{3}$," Oak Ridge National Laboratory Report, ORNL-TM-2256, October 1968. 


\section{DISTRIBUTION LIST FOR ANLTD/TM00-09}

\section{Internal}
R.K. Ahluwalia
T. Hua
D.L. Smith
S. Bhattacharyya
C. Johnson
D.-K. Sze
M. Billone
J. Laidler
H. Tsai
J. Brooks
S. Majumdar
R. Valentin
Y. Chang
V. Maroni
D. Wade
D. Ehst
R. Mattas
R.W. Weeks
P. Finck
K. Natesan
T. Yule
Y. Gohar (10)
J.-H. Park
I. Gomes
B. Picologlou
D. Gruen
R. Poeppel
A. Hassanein
C. Reed
D. Hill
W. Shack

\section{External}

DOE/OSTI, for distribution (2)

ANL-E Library

ANL-W Library

J. Anderson, Los Alamos National Laboratory, Los Alamos, NM

R. Aymar, ITER Garching, Garching, Germany

C. Baker, University of California, San Diego, CA

D. Baldwin, General Atomic, San Diego, CA

S. Berk, U.S. Department of Energy, Germantown, MD

E. E. Bloom, Oak Ridge National Laboratory, Oak Ridge, TN

C. Bolton, U.S. Department of Energy, Germantown, MD

R. Causey, Sandia National Laboratories, Livermore, CA

E. Cheng, TSI Research Inc., San Diego, CA

V. Chernov, Bochvar Research Institute of Inorganic Materials, Moscow, Russia

V. Chuyanov, ITER Garching, Garching, Germany

S.A. Cohen, Princeton Plasma Physics Laboratory, Princeton, NJ

R. Conn, University of California, San Diego, CA

R. Dagazian, U.S. Department of Energy, Germantown, MD

W. Dove, U.S. Department of Energy, Germantown, MD

M. Eid, CEA, Gif-sur-Yvette, France

L. El-Guebaly, University of Wisconsin, Madison, WI

G. Emmert, University of Wisconsin, Madison, WI

V. Evtikhin, State Enterprise Red Star, Moscow, Russia

O. Filatov, Efremov Scientific Research Institute, St. Petersburg, Russia

$U$. Fischer, Forschungszentrum Karlsruhe, Germany

M. Fuetterer, CEA, Gif-sur-Yvette, France

M. Gasparotto, ENEA, Frascati, Italy 
L. Giancarli, CEA, Gif-sur-Yvette, France

R. Goldston, Princeton Plasma Physics Laboratory, Princeton, NJ

H. Kawamura, Japan Atomic Energy Research Institute, Oarai-Machi, Japan

I. Kirillov, Efremov Scientific Research Institute, St. Petersburg, Russia

C. Konno, Japan Atomic Energy Research Institute, Tokai-mura, Japan

R. A. Krakowski, Los Alamos National Laboratory, Los Alamos, NM

G. Kulcinski, University of Wisconsin, Madison, WI

T. Kuroda, Japan Atomic Energy Research Institute, Naka, Japan

G. Lucas, University of California, Santa Barbara, CA

I. Lyublinski, State Enterprise Red Star, Moscow, Russia

H. Maekawa, Japan Atomic Energy Research Institute, Japan

S. Malang, Forschungszentrum Karlsruhe, Karlsruhe, Germany

D. Markovskij, Kurchatov Institute, Moscow, Russia

W. Marton, U.S. Department of Energy, Germantown, MD

Y. Martynenko, Kurchatov Institute, Moscow, Russia

R. Matera, URC-IHCP, Ispra, Italy

S. Matsuda, Japan Atomic Energy Research Institute, Naka, Japan

H. Matsui, Tohoku University, Sendai, Japan

K. McCarthy, Idaho National Engineering and Environmental Laboratory, Idaho Falls, ID

R. Miller, University of California, San Diego, CA

R. Moir, Lawrence Livermore National Laboratory, Livermore, CA

S. Molokov, Coventry University, Coventry, United Kingdom

F. Najmabadi, University of California, San Diego, CA

W. Nevins, Lawrence Livermore National Laboratory, Livermore, CA

R. Nygren, Sandia National Laboratories, Albuquerque, NM

Y. Ohara, Japan Atomic Energy Research Institute, Naka, Japan

A. Opdenaker, U.S. Department of Energy, Germantown, MD

R. Parker, Massachusetts Institute of Technology, Cambridge, MA

J. Perkins, Lawrence Livermore National Laboratory, Livermore, CA

D. Petti, Idaho National Engineering and Environmental Laboratory, Idaho Falls, ID

A. Pizzuto, ENEA, Frascati, Italy

J. Reimann, Forschungszentrum Karlsruhe, Karlsruhe, Germany

M. Sawan, University of Wisconsin, Madison, WI

K. Schultz, General Atomic, San Diego, CA

G. Shatalov, Kurchatov Institute of Atomic Energy, Moscow, Russia

Yu.A. Sokolov, Minatom, Moscow, Russia

M. Solonin, Bochvar Research Institute of Inorganic Materials, Moscow, Russia

W.M. Stacey, Georgia Institute of Technology, Atlanta, GA

D. Steiner, Rensselaer Polytechnic Institute, Troy, NY

Y. Strebkov, Research and Development Institute of Power Engineering, Moscow,

Russia

I. Sviatoslavsky, University of Wisconsin, Madison, WI

H. Takatsu, Japan Atomic Energy Research Institute, Tokyo, Japan

T. Terai, University of Tokyo, Tokyo, Japan

M. Tillack, University of California, San Diego, CA 
M. Ulrickson, Sandia National Laboratories, Albuquerque, NM

J. Van der Laan, NRG, Petten, Netherlands

R. Van der Schaaf, NRG, Petten, Netherlands

E. P. Velikov, Kurchatov Institute of Atomic Energy, Moscow, Russia

J. Vetter, Forschungszentrum Karlsruhe, Germany

F.W. Wiffen, U.S. Department of Energy, Germantown, MD

C. Wong, General Atomics, San Diego, CA

S. Zinkle, Oak Ridge National Laboratory, Oak Ridge, TN

Bibliothek, Max-Planck-Institute fur Plasmaphysik, Germany

C.E.A. Library, Fontenay-aux-Roses, France

Librarian, Culham Laboratory, England

Thermonuclear Library, Japan Atomic Energy Research Institute, Japan

University of Illinois, Fusion Studies Laboratory

University of Illinois, Grainger Engineering Library Information Center 